\title{
Bienes y condiciones de vida de las familias campesinas del Norte de Castilla a finales del Antiguo Régimen: Miranda de Ebro y su jurisdicción (1700-1850) ${ }^{1}$
}

\section{Assets and living conditions of peasant families in Norther Castilla at the end of the Ancient Regime: Miranda de Ebro and its jurisdiction (1700-1850)}

\author{
Juan Manuel Bartolomé Bartolomé \\ Universidad de León \\ jmbarb@unileon.es \\ https://orcid.org/0000-0001-5905-1468
}

Fecha de recepción: 19-05-2020

Fecha de aceptación: 25-09-2020

\section{RESUMEN}

Tomando como fuente primordial los protocolos notariales y los inventarios de bienes, el objetivo fundamental es analizar, mediante una metodología cuantitativa y cualitativa, los patrimonios y las permanencias y los cambios en la cultura material, condiciones de vida y apariencias de las familias campesinas de las localidades periféricas castellanas, Miranda de Ebro y su jurisdicción tratando de averiguar las continuidades y la llegada de novedades en los interiores domésticos y en las apariencias externas, a finales del Antiguo régimen, y también las analogías y diferencias con los campesinos del interior castellano leonés. ¿Al ser poblaciones más próximas a Europa y en zonas de transición, la llegada de la modernidad fue más temprana que en las familias del interior? La principal conclusión es que las familias de la zona norte castellana presentarán en el periodo analizado rasgos distintivos respecto al campesinado de las zonas del interior castellano leonés.

Palabras clave: familias, campesinos, cultura material, condiciones de vida

Topónimos: zona norte castellana

Período: siglos XVIII-mediados XIX.

ABSTRACT

The main objective of this research, which uses public notary documents as the main source, is analysis of personal assets by employing quantitative and qualitative methodology. We have

1 HAR2017-84226-C6-4-P: Familias, cultura material, apariencia social y civilización. Identidades y representaciones en el interior peninsular (1500-1850); Ministerio de Economía, Industria y Competitividad. Proyectos de I+D del programa estatal de 'Excelencia', 2018-2020. 
focused on both the changes and the ongoing behavior in the material culture, living conditions and appearance of the peasant families of the outlying localities of Castile such as Miranda de Ebro and its jurisdiction. On the one hand, we have studied the arrival of novelties in both interiors and exteriors at the end of the Ancient Regime, and on the other, the similarities and differences vis-à-vis the peasants who lived in the interior of Castile.

Our working hypothesis is that, among the population in these peripheral zones, closer to Europe, the arrival of modernity was earlier than in the families living in the interior. The main conclusion is that the families of northern Castile presented distinctive features in comparison with the peasantry of the interior areas of Castile and León.

Key words: families, peasants, material culture, living conditions.

Toponyms: northen Castile.

Period: $18^{\text {th }}-$ mid-19 $19^{\text {th }}$ century.

\section{INTRODUCCIÓN}

El temor al cambio, el fuerte peso de la tradición, la influencia de la opinión del entorno familiar y de la comunidad, y los mensajes moralistas, principalmente de los párrocos y los sermones misionales, frenaban las posibilidades de cambio de las comunidades rurales castellanas en el Antiguo Régimen. En este sentido, cabe recordar que algunos campesinos a pesar de tener medios económicos para poder permitírselo no quisieran destacar con excesos: "ni se les ocurría"2. Ante la persuasión de las novedades las galas tenían que acomodarse a la posición familiar y no provocar el desprecio popular en intentar parecer lo que no se $\mathrm{era}^{3}$.

No obstante, avanzado el siglo XVIII y en la primera mitad del XIX se introdujeron novedades en las condiciones de vida, interiores domésticos y apariencias externas: vestir y adornar el cuerpo de las familias campesinas castellanas, rompiendo la imagen historiográfica tradicional de un campesinado homogéneo e inmerso en la tradición ${ }^{4}$. En estas zonas del interior castellano se apreciará, en definitiva, la llegada de elementos

2 R. Maruri Villanueva, "La historia social del consumo en la España moderna: un estado de la cuestión", Studis, 42, (2016), pp. 267-304.

3 "Porque, al fin, por más que la mona se vista de seda, mona se queda", J. F. Isla, Historia del famoso predicador fray Gerundio de Campazas, alias Zotes (edición de Rodríguez Cepeda, t. II, cap. IX, 1995, p.852.

4 J. M. Bartolomé Bartolomé, "Condiciones de vida y privacidad cotidiana del campesinado leonés de Tierra de Campos: La comarca de Sahagún en el siglo XVIII", en F. Núñez Roldán (coord.), Ocio y vida cotidiana en el mundo hispánico moderno, Sevilla, Universidad de Sevilla, 2007, pp. 403- 416; R. M. Dávila Corona y J. M. Bartolomé Bartolomé, "Condiciones de vida y pautas de consumo en la Castilla rural (1750-1850)", en Apariencias contratadas..., p. 79; J. M. Bartolomé Bartolomé, "Pobrezas y riquezas campesinas castellano leonesas: Contrastes en las formas de vida y consumo (1700-1850)", Tiempos Modernos, 8, 32, (2016), pp. 419-431; M. García Fernández, "Vidas cotidianas en el entorno rural del Duero: niveles de consumo comparados. Siglo XVIII", en Campo y campesinos en la España Moderna, XII Reunión Científica de la Fundación Española de Historia Moderna, León, 2012, p. 1446; M. J. Pérez Álvarez y L. Rubio Pérez, "Familia y comunidad rural. Modelos agrarios, colectivismo social y comportamientos familiares en la provincia de León durante la Edad Moderna", Studia Histórica, 36, (2014), pp. 177-2012. Para un balance sobre los estudios del campesinado véase L. Rubio Pérez, "Campo, campesinos y cuestión rural en Castilla la Vieja y en el Reino de León durante la Edad Moderna. Estado de la cuestión, claves y valoraciones de conjunto", Studia Histórica, 29, (2007), pp. 131-177. 
conectados con la modernidad y la civilización ${ }^{5}$, postulados por las reformas ilustradas ${ }^{6}$, siguiendo la estela de las nuevas modas urbanas burguesas ${ }^{7}$.

Los objetivos que planteamos en este estudio son los siguientes: por una parte, analizar los patrimonios —-tipología, estructura, dinámica- de las familias campesinas de una zona periférica castellana: Miranda de Ebro y las localidades de su jurisdicción, tratando de averiguar las continuidades y las novedades en relación con los comportamientos comparativos de las familias campesinas conocidas, preferentemente más cercanas territorialmente y más afines por las estructuras agrarias. Y por otra parte, adentrarnos en sus condiciones de vida, tratando de descubrir si su posición geográfica de frontera norte, más próxima a las influencias europeas, resulta relevante a la hora de apreciar un adelantamiento cronológico de los cambios y la mayor propensión a las modas tanto en los interiores domésticos, espacios y objetos de los mismos, como en la apariencia externa del cuerpo: vestimenta y adornos complementarios.

Para abordar estos objetivos hemos utilizado ensayos y obras de literatura de la época, fuentes catastrales (Catastro del Marqués de la Ensenada); notariales (protocolos notariales de Burgos y Miranda de Ebro) y municipales (Archivo Municipal de Miranda de Ebro). Dentro de la gran variedad de documentos notariales que tienen interés para este tipo de estudios - cartas de dote, testamentos, obligaciones, escrituras de compra y venta y otras-, nos interesan principalmente los inventarios de bienes (localizados de forma sorpresiva más en el Archivo Municipal de Miranda de Ebro que en el Archivo Histórico Provincial de Burgos $^{8}$ ) tanto los realizados en vida como post-mortem. La importancia de los inventarios como fuente principal para poder realizar este tipo de estudios ha sido muy cuestionada, dando origen a una larga discusión ${ }^{9}$. No obstante, últimamente incluso Jean de Vries reconoce sus virtudes, aunque con las limitaciones ya señaladas de recoger más el stock de productos que su flujo, lo cual sigue siendo un problema para los estudios centrados en la denominada historia del consumo ${ }^{10}$. Al final, hemos conseguido reunir una muestra de 36 inventarios postmortem de familias campesinas. Son inventarios que ofrecen grandes posibilidades de estudio ya que en general figuran todos los bienes, no sólo los mobiliarios, y además están tasados, valorados. Sin embargo, se ha de advertir que la mayoría de este tipo se localizan en la segunda mitad del siglo XVIII y primera mitad del $\mathrm{XIX}$, en cambio en la primera mitad del XVIII predominan los no tasados.

5 Dentro del proceso de "civilización" de costumbres ver: N. Elias, El proceso de la civilización. Investigaciones sociogenéticas y psicognéticas, México, 1987.

6 J. Ma. Imízcoz Beunza, "Una modernidad diferencial. Cambio y resistencias al cambio en las tierras vascas, 1700-1833", Historia Social, 89, (2017), pp. 79-102; o "Costumbres en tensión. El proceso de la civilización en las tierras vascas, de las costumbres compartidas a la fractura de la comunidad (1700-1833)", en J. M. Imízcoz Beunza, M. García Fernández y J. Esteban Ochoa. (coords.), Procesos de civilización: cultura de élites, culturas populares. Una historia de contrastes y tensiones (siglos XVI-XIX), Bilbao, Universidad del País Vasco, 2019.

7 J. Cruz Valenciano, El surgimiento de la cultura burguesa. Personas, hogares y ciudades en la España del siglo XIX, Madrid, Siglo XXI, 2014.

8 Agradezco al responsable del Archivo Municipal de Miranda de Ebro, Carlos Diez Javiz, su amabilidad y su disposición a la hora de facilitarnos la consulta de la documentación.

9 Existe información bibliográfica sobre esta cuestión en el trabajo de A. Eiras Roel, "Tipología documental de los protocolos gallegos", en La Historia social de Galicia en sus fuentes de protocolos, Santiago de Compostela, pp. 28-29. También: B. Yun Casalilla, "Inventarios post-mortem, consumo y niveles de vida del campesinado del Antiguo Régimen (Problemas metodológicos a la luz de la investigación internacional)", en VII Congreso de Historia Agraria, Salamanca, 1997, pp. 46-53.

10 J. De Vries, La revolución industriosa. Consumo y economía doméstica desde 1650 hasta el presente, Barcelona, 2009, p. 158. 


\section{MIRANDA DE EBRO Y SU JURISDICCIÓN A MEDIADOS DEL SETECIENTOS}

Las localidades objeto de estudio están emplazadas actualmente en el norte de la provincia de Burgos, la Rioja y Álava. Son y eran, por lo tanto, poblaciones fronterizas, que tienen como centro de jurisdicción en el siglo XVIII a Miranda de Ebro.

Se trata de localidades de realengo de muy escaso tamaño demográfico, ya que exceptuando Pancorbo, con 288 vecinos según el Catastro de Ensenada, y la cabeza central de la jurisdicción, Miranda de Ebro, con 1.625 habitantes según el Censo de Floridablanca de $1787^{11}$, el resto se sitúa entre los 16 vecinos, 3 viudas y 3 pastores de Villaseca y los 30 vecinos, unos 1.200 habitantes, de Cellórigo.

A través de la información que proporciona el Catastro ensenadino y los inventarios post-mortem, podemos aproximarnos a sus principales cultivos. Así, frente a un reducido regadío, centrado en el terrazgo más próximo de las huertas, predominan los cereales del secano, trigo, cebada, centeno y avena -explotados de forma extensiva, donde el barbecho es fundamental- y el viñedo. Los árboles frutales más abundantes son los ciruelos, manzanos, perales, cerezos, membrillos y nogales. También los vecinos pueden utilizar los prados en común y sobre todo los montes o sierras, bien para apacentar a sus ganados 0 para aprovechar la leña, ya que en general no son arrendados pero siempre se realizó un aprovechamiento comunal de los mismos ${ }^{12}$.

Una ganadería abundante, donde junto a los animales de labor -bueyes, mulas y machos, y caballos desde mediados del siglo XVIII- destacan los numerosos rebaños de ovejas, con los imprescindibles cerdos para completar sus economías domésticas.

En definitiva, un paisaje y una economía agraria muy similar a la de los campesinos leoneses y castellanos, sobre todo a los vallisoletanos y terracampinos de la zona de Sahagún.

Estas localidades, principalmente la más populosa de Miranda de Ebro, como ya se ha señalado, son muy interesantes por su posición geográfica, zonas de frontera entre Castilla y las provincias vascas, y puerto seco de Castilla ${ }^{13}$, lo cual facilitaba la temprana llegada de productos, textiles y otros semiperecederos, del País Vasco y de Europa, principalmente desde la vecina Francia ${ }^{14}$.

\section{PRIMERA MITAD DEL SIGLO XVIII: EL RITMO DE LA TRADICIÓN}

Un problema inicial para la primera mitad del siglo XVIII, tal como ya se ha adelantado, es que la mayoría de los inventarios post-mortem no ofrecen una tasación de los objetos. Por ello, es imposible realizar un estudio comparativo de sus niveles patrimoniales y la composición cuantitativa de su riqueza. Sólo podemos acercarnos a sus condiciones de vida a través de un análisis cualitativo.

A modo de ejemplo, podemos conocer la riqueza patrimonial del molinero Pedro de Frías, cuyos bienes fueron tasados en la relevante cantidad de 19.048 reales, cifra muy

11 Censo de Floridablanca 1787. Tomo III. Comunidades Autónomas de la Submeseta Norte, INE, 2 vols., NIPO web: 729-16-002-2.

12 Así, en Miranda de Ebro se hace referencia a un monte común de 200 fanegas; Catastro del Marqués de la Ensenada. Respuestas Generales. Portal de Archivos Españoles en Red (Pares).

13 En el año 1634 se hace referencia en un documento municipal, relacionado con los impuestos, que al ser Miranda "el último lugar y puerto seco de Castilla se paga y se ha pagado la sisa del vino, aceite y carne que pasa por ella para las provincias de Álava, Guipúzcoa y Vizcaya"; Archivo Histórico Municipal de Miranda de Ebro (AHMME), Legajo 155, doc. 5. En el siglo XVIII el control sobre las mercancías recaerá en la Real Aduana de Orduña.

14 En el año 1611 de visitan las tiendas y los mercaderes que acuden a las ferias de Miranda y ya aparecen "piezas de algodón", calzones de Vitoria, hilo blanco de Francia y "varas de Ruán"; id., Legajo 97, doc. 8. 
superior a las medias de la zona en la segunda mitad del siglo XVIII y primera del XIX, y con escasas deudas, tan sólo 2.090 reales $^{15}$. Entre los mismos destacan las tierras que explota, principalmente de cereal -42 fanegas $^{16}$, las cuales parece llevar a renta, siendo propiedad del conde de Corzana, por las que paga 110 fanegas anuales- y una copiosa cabaña ganadera conformada por dos bueyes, tres machos, treinta ovejas y dos cerdos. El inventario informa de una casa y un establo, que suponemos anexo a la misma, que también servía de pajar. Lo más relevante es que podemos reconstruir las dependencias de la casa: portal, cocina y dos cuartos, uno junto a la panera y el otro de "arriba que sirve de sala". De estos espacios domésticos el más importante es la cocina, al igual que en el resto de la mayoría del campesinado castellano y leonés. Era el lugar preferencial, a veces casi único, destinado no sólo para comer sino también para habitar y descansar (dormir junto al fuego ${ }^{17}$. Así, en su cocina, además de los útiles propios para cocinar trébedes, almireces, cazos, asadores, etcétera- hay dos camas, en una de las cuales, en madera de haya, fallecería. En definitiva, toda la vida familiar, incluyendo los actos más íntimos, y la presencia de animales domésticos, se desarrollaron en ese reducido espacio, sorprendiendo a los viajeros extranjeros ${ }^{18}$.

Si nos fijamos en los inventarios postmortem no tasados, en total 14, observamos que el resto del campesinado también dispondrán de explotaciones agrarias, que parecen en general propias, muy dignas e incluso superiores a los restantes campesinos leoneses y castellanos, con una media de 26 fanegas de cereal ${ }^{19} \mathrm{y}$ ocho fanegas de viñedo. ${ }^{20}$ Animales de tiro, bueyes y machos, con medias también por encima ${ }^{21}$, y sobresalientes rebaños lanares $^{22}$.

15 Idem, Legajo 821, Documento 34.

16 Las medidas de las tierras vienen dadas en celemines y yugadas y las del viñedo en obradas. Según Santiago Ibáñez Rodríguez cada yugada equivale a una fanega y cuatro obradas a una fanega; S. Ibáñez Rodríguez, "La necesidad de medir. La metrología agraria del Antiguo Régimen en la Rioja", Brocar, 19, (1995), pp. 131-163.

17 Igual que ocurría en Vitoria; P. Manzanos Arreal, "La casa y la vida material en el hogar. Necesidades vitales y niveles de vida en la Vitoria del siglo XVIII", en J. M. Imízcoz (coord.), Vida cotidiana en Vitoria en la Edad Moderna y Contemporánea, San Sebastián, Txertoa, 1995, pp. 205-206. También en La Mancha (en Montiel) la cocina era un espacio diverso y multifuncional: de necesidad, de relación social y familiar y para dormir, con muebles que podían servir de cama, como un banco de pino o una puerta vieja de madera con tres almohadas que servía de tarima; C. Hernández López, "Cultura material y especialización de la casa (Campo de Montiel, 1650-1850)", en J. M. Bartolomé Bartolome y M. García Fernández (dirs.), Apariencias contrastadas: contraste de apariencias. Cultura material y consumos de antiguo régimen, León, Universidad, 2012, p.27. Y lo mismo sucedía en la Galicia occidental o el Baixo Minho donde la mayoría de las casas de los campesinos suelen ser de pequeño tamaño y sin espacios delimitados conviviendo personas y animales. $O$. Rey Castelao, "Casas y cosas en la Galicia occidental en el siglo XVIII", Cuadernos de Historia Moderna, extra 14, (2015), pp. 221-223; O. Barbosa Vilaça, "A casa rural do Baixo Minho (1750-1810)", Revista de Estudos históricos, 29, 57, (2016), pp. 235-262

18 C. Casado Lobato y A. Carrerira Vérez, Viajeros por León. Siglos XII-XIX, Madrid, 1985 (Soutthey, R., p. 220).

19 Sobresale Francisco de Bustos, vecino de Cellorigo, quien en 1724 tendrá 60 fanegas de cereal, 33 de trigo, 8 de centeno y 11 de cebada, 7 de avena, 1 de habas y 1 de yeros; AHMME, Legajo 476.

20 En el viñedo, es de destacar a Miguel Salazar, vecino de Villaseca, que en 1731 tiene 47 obreros u obradas, unas doce fanegas de viña, y entre sus bienes inventariados hay sesenta cántaras de vino de la cosecha del año anterior; ibídem.

21 Francisco de Bustos tendrá nada menos que cuatro mulas; ibídem.

22134 cabezas; ibídem. 
Las diferencias en las condiciones y estilo de vida ${ }^{23}$ vendrán dadas más por las cantidades de piezas y por la calidad de las mismas que por la llegada de novedades, tanto en los objetos como en sus materias primas de elaboración, al igual que sucedía en el mundo rural próximo castellano-leonés. Del mismo modo, a mayor nivel de riqueza patrimonial más cantidad y calidad de los objetos de consumo, pero de los básicos, no de los más lujosos y ostentosos: ni en la decoración de las estancias, ni en la cubertería de oro y plata de la casa o las joyas y alhajas de adorno personal. Así, son frecuentes en la ropa de vestir masculina los calzones, camisas, coletos, jubones, ropillas, anguarinas o las capas, confeccionados generalmente con tejidos de lana muy rústicos: bayeta o sayal. En las prendas femeninas abundan los jubones, camisas, mantillas, justillos, enaguas, delantales, sayas, capillos, mantos y almillas, siendo las más codiciadas las de paño bien negro o pardo, aunque también hay algún jubón de droguete de colores y tocadores bordados ${ }^{24}$. La ropa que cubría las camas constaba de lenzuelos, jergones, mantas, sábanas, etc., de lienzo generalmente casero y de lana para las mantas. La ropa de casa -manteles, paños, servilletas- también estaba presente, pero con predominio de los más humildes: de terliz, "de grano de cebada" o "manteles ordinarios de granillo". Entre las piezas del mobiliario doméstico, junto a las abundantes camas, presentes no sólo en la cocina sino también en los cuartos que se utilizan como salas, hay mesas, bancos con o sin respaldo, alguna silla, bufetes, arcones y, sobre todo arcas, destinadas a guardar ropa u objetos personales y productos agrarios ${ }^{25}$. El nogal es el material preferido para la elaboración de estos muebles. En los útiles de la cocina sobresalen las calderas, junto con los cazos, sartenes, trébedes, almireces y también, en menor cuantía, parrillas para asar los alimentos ${ }^{26}$. Los objetos de oro o plata y cubertería, y principalmente los de adorno personal, son muy escasos; únicamente en el inventario de la viuda Brígida Marrón se hace referencia a tres cucharas y una taza de plata y un broche de plata ${ }^{27}$. Finalmente, lo objetos decorativos se limitan a estampas religiosas, tan comunes y conocidas en todas las familias, y ocasionalmente a alguna cortina de "grano de cebada" para la alcoba ${ }^{28}$ o a dos cuadros de "la pintura de Sevilla"29.

No obstante, en este panorama enmarcado en las tendencias ya conocidas para el campesinado del interior castellano, destaca como rasgo distintivo para esta zona norte de frontera y más próxima a las influencias europeas, la presencia de novedades reflejadas

23 Los apartados de la riqueza mobiliaria que hemos agrupado metodológicamente para su estudio son los siguientes: decoración de la casa (objetos religiosos), mobiliario doméstico, útiles de cocina (donde se incluyen los del menaje de la mesa como la vajilla y la cristalería), ropa de vestir, la del hogar, libros y objetos de oro y plata (alhajas o joyas).

24 Un tocador bordado y franja de seda negra entre la ropa personal de Brígida Marrón, viuda y vecina de Cellórigo, cuyo inventario se realiza en 1725; AHMME, Legajo 511.

25 El mencionado campesino, Pedro Frías, tiene en el ya señalado "cuarto de arriba que sirve de sala: tres camas, un bufete de nogal y nada menos que ocho arcas, todas de nogal y en algunas se especifica que son de "echar trigo";:AHMME, S/C

26 Como ejemplo, en Miguel de Salazar, vecino de Villaseca, en 1731, fecha del inventario post-mortem, hay unas "parrillas de fierro medianas" AHMME, S/C. Aunque hay que tener en cuenta que la carne de cerdo era la más extendida entre el consumo de los campesinos. H. Sobrado Correa, H., "Algunas notas acerca de la vida cotidiana del campesinado gallego en la Edad Moderna", Revista Portuguesa de História, XLVII, (2016), p.144. R. Sarti, Vida en familia. Casa, comida y vestido en la Europa moderna, Barcelona, 2002, p. 219

27 Ibídem.

28 Inventario de Brígida Marrón; AHMME, S/C.

29 Inventario de Miguel de Salazar; AHMME, S/C. 
sobre todo en la ropa personal. Así, en cuatro inventarios se observa la llegada de las nuevas fibras textiles: el algodón ${ }^{30}$ y las nuevas prendas de la moda francesa: casaca, chupa y calzón ${ }^{31}$ junto a paños bordados, sobrepelliz y un gorguerillo de ruán.

\section{LA IMPORTANCIA DE LOS BIENES MOBILIARIOS Y LAS NOVEDADES FRANCESAS EN LA SEGUNDA MITAD DEL SIGLO XVIII}

Para la segunda mitad del siglo XVIII disponemos de más inventarios tasados, lo cual permite calcular la media de riqueza patrimonial, situada en 14.950 reales, con un pasivo-deudas de tan sólo un 7'6 \%. Son valores superiores a los del campesinado leonés de la zona de Sahagún y El Bierzo, los cuales no llegan a los 10.000 , pero inferiores a los vallisoletanos de San Pedro de Latarce, donde la media para la segunda mitad del siglo XVIII es de 42.900 reales $^{32}$. Estarían más próximos a los campesinos leoneses más pudientes de La Vega Baja del Esla o de las comarcas de La Bañeza y Astorga ${ }^{33}$. Como es lógico estas medias encubren fuertes contrastes, entre unos máximos de 56.773 reales de valor patrimonial y el más inferior de únicamente 2.619 reales $^{34}$.

Cuadro 1. Riqueza patrimonial del campesinado. Miranda de Ebro y su jurisdicción, 1750-1850 (reales)

\begin{tabular}{|c|c|c|c|c|}
\hline & ACTIVO & PASIVO & LÍQUIDO & MEDIAS \\
\hline $\begin{array}{c}2^{\mathrm{a}} \text { Mitad S. XVIII } \\
(14)\end{array}$ & 226.463 & 17.159 & 209.304 & 14.950 \\
\hline $\begin{array}{c}1^{\mathrm{a}} \text { Mitad S. XIX } \\
(7)\end{array}$ & 71.742 & 12.467 & 59.275 & 8.468 \\
\hline
\end{tabular}

Fuente: A.H.M.M.E., 21 Inventarios de bienes. Entre paréntesis la muestra de inventarios con los bienes tasados.

30 En el inventario de Pedro de Frías se especifica un "justillo de mujer de cotonia"; ibídem.

31 En Miguel de Salazar la ropa del difunto está en consonancia con las innovaciones introducidas desde Francia a comienzos del siglo XVIII: "dos capotes de paño, cuatro camisas, cuatro corbatas, tres pares de calzoncillos, dos casacas, dos chupas de paño buenas, una montera, un sombrero y dos pares de calzones de paño medianos"; ibídem.

32 R. M. Dávila Corona y J. M. Bartolomé Bartolomé,“Condiciones de vida y pautas de consumo...”, p. 79.

33 En la primera mitad del siglo XVIII la media es de 13.000 reales. En cambio, en la Vega Baja del Esla en 1760-1789 se produce un incremento situándose en 21.218 reales y en Astorga-La Bañeza a finales del siglo llegan también a la cifra de 21.031 reales; J.M. Pérez García, "Niveaux de vie et traditions culturelles dans les campagnes du León entre 1700-et 1850", en Histoire \& Sociétés Rurales, 8, (1997), p. 66. J.M. Bartolomé Bartolomé, "Condiciones de vida y pautas de consumo del campesinado leonés de La Bañeza y Astorga (1750-1850)", en El mundo rural en la España Moderna. VIIa Reunión Científica de la Fundación Española de Historia Moderna, Cuenca (2004), pp. 589-590.

34 El superior es de Diego López de Torre y su esposa, Letrona de Fontecha, vecinos de Comunión, y el segundo es de la viuda Catalina Barrio, vecina de Puente la Rada; AHMME, Legajos 711 y 730. 
En la estructura de sus patrimonios hay un claro predominio de los bienes raíces, casas y sobre todo tierras, y semovientes, lo cual es lógico al tratarse de economías campesinas. De este modo, las casas, corrales y pajares suponen un 14 '9 \% de la riqueza ${ }^{35}$, las tierras el 25 '9 \% y el ganado el 9'5 \%. A nivel comparativo, constituyen porcentajes inferiores a los del campesinado leonés de la comarca de Sahagún de Tierra de Campos $^{36}$, lo cual determina la mayor valoración de los bienes mobiliarios, que se acercan casi a la mitad de toda la riqueza patrimonial, con el 44'7\%.

Cuadro 2. Distribución de la riqueza patrimonial del campesinado. Miranda de Ebro y su jurisdicción, 1750-1850 (en reales y porcentajes sobre el valor del stock inventariado)

\begin{tabular}{|c|c|c|c|c|}
\hline & \multicolumn{2}{|c|}{ 2 $^{\text {a MITAD s. XVIII }}$} & \multicolumn{2}{c|}{$1^{\text {a MITAD s. XIX }}$} \\
\hline & REALES & $\%$ & REALES & $\%$ \\
\hline $\begin{array}{c}\text { Casas, dependencias } \\
\text { complementarias }\end{array}$ & 33.764 & $14^{\prime} 9$ & 22.006 & $30^{\prime} 7$ \\
\hline Tierras & 58.541 & $25^{\prime} 9$ & 22.086 & $30^{\prime} 8$ \\
\hline Ganados & 21.359 & $9 ' 5$ & 6.987 & $9^{\prime} 8$ \\
\hline Bienes mobiliarios & 112.799 & $44^{\prime} 7$ & 20.663 & $28^{\prime} 7$ \\
\hline
\end{tabular}

Fuente: A.H.M.M.E., 21 Inventarios de bienes

Es cierto que las medias de los bienes mobiliarios son más elevadas en estas familias campesinas norteñas, promediando 6.031 reales, que entre los campesinos leones e incluso superan a los más pudientes de la Vega del Esla que no llegarán a los 5.000 reales $^{37}$. Ello es debido al fuerte peso que tienen las partidas relacionadas con las cantidades de dinero que les adeudaban, un 31'5 \%, y a las elevadas existencias que hay en sus paneras, arcas y cubas, de grano y vino de sus cosechas, productos agrarios que son tasados con cifras que suponen el 23'7 \% de la riqueza mobiliaria. Sin embargo, los bienes conectados con las condiciones y estilo de vida descienden a un 23'7 \% y, lo que es más clarificador, sus medias son de tan sólo 1.429 reales.

35 La alta participación de las casas es debido a la presencia de una casa mesón de un campesino, José de Salazar, vecino de Berguenda, tasado en 18.643 reales, si exceptuamos este caso los porcentajes de las casas descienden casi a la mitad; AHMME.

3623 '4 \% para las viviendas, 31'6 \% para las tierras y 17'3 \% para la ganadería. J. M. Bartolomé Bartolomé, "Condiciones de vida y privacidad cotidiana ...", pp. 403-416

37 En Sahagún 2.707 reales y en el Bierzo Bajo tan sólo 1.008 reales. Ibidem. 
Cuadro 3. Distribución de la riqueza mobiliaria del campesinado. Miranda de Ebro y su jurisdicción, 1750-1850 (en reales y porcentajes sobre el valor del stock inventariado)

\begin{tabular}{|c|c|c|c|c|}
\hline & \multicolumn{2}{|c|}{$2^{\mathrm{a}}$ MITAD s. XVIII } & \multicolumn{2}{|c|}{$1^{\mathrm{a}}$ MITAD s. XIX } \\
\hline & REALES & $\%$ & REALES & $\%$ \\
\hline Grano & 19.348 & $23{ }^{\prime} 0$ & 1.141 & $8^{\prime} 9$ \\
\hline Vino & 626 & $0{ }^{\prime} 7$ & -- & -- \\
\hline $\begin{array}{l}\text { Fibras textiles y } \\
\text { productos despensa }\end{array}$ & 1.843 & $2 ' 2$ & 171 & $1 ' 3$ \\
\hline Deudas a favor & 26.626 & $31 ’ 5$ & -- & -- \\
\hline Dinero en efectivo & 170 & $0 ’ 2$ & -- & -- \\
\hline útiles labranza & 5.090 & $6{ }^{\prime} 0$ & 1.873 & $14^{\prime} 5$ \\
\hline Maderas & 10.724 & $12 ' 7$ & -- & -- \\
\hline Ropa, alhajas & 20.011 & $23{ }^{\prime} 7$ & 9.735 & $75^{\prime} 3$ \\
\hline Total & \multicolumn{2}{|c|}{84.438} & \multicolumn{2}{|c|}{12.900} \\
\hline Medias & \multicolumn{2}{|c|}{6.031} & \multicolumn{2}{|c|}{1.846} \\
\hline
\end{tabular}

Fuente: A.H.M.M.E., 21 Inventarios de bienes.

Cuadro 4. Condiciones de vida del campesinado de Miranda de Ebro y su jurisdicción (en reales y porcentajes sobre el valor del stock de bienes inventariados)

\begin{tabular}{|c|c|c|c|c|}
\hline & \multicolumn{2}{|c|}{$2^{\mathrm{a}}$ MITAD s. XVIII } & \multicolumn{2}{c|}{$1^{\text {a }}$ MITAD s. XIX } \\
\hline & REALES & $\%$ & REALES & $\%$ \\
\hline Decoración de la casa & 257 & $1^{\prime} 3$ & 53 & 0 '5 \\
\hline Mobiliario de la casa & 3.125 & $15^{\prime} 6$ & 1.660 & $17^{\prime} 0$ \\
\hline Ropa personal & 3.661 & $18^{\prime} 3$ & 1.186 & $12^{\prime} 2$ \\
\hline Ropa cama & 8.896 & $44^{\prime} 5$ & 3.504 & $36^{\prime} 0$ \\
\hline Ropa casa & 1.143 & $5^{\prime} 7$ & 1.473 & $15^{\prime} 1$ \\
\hline Joyas, alhajas & 848 & $4^{\prime} 3$ & 389 & $4^{\prime} 0$ \\
\hline Libros & 9 & 0 '0 & 125 & $1^{\prime} 3$ \\
\hline Total & \multicolumn{3}{|c|}{20.011} & 9.735 \\
\hline Medias & 1.429 & & 1.391 \\
\hline
\end{tabular}

Fuente: A.H.M.M.E., 21 Inventarios de bienes 
Son valores medios superiores a los de Sahagún, con 839 reales, y los más bajos de El Bierzo, 744 reales, y más distantes a los vallisoletanos, unos 2.995 reales para la segunda mitad del siglo XVIII. No obstante, las diferencias no son tan fuertes como ocurría con la valoración de todo el patrimonio, lo cual indica, por una parte, la gran relevancia que tenían en la estructura patrimonial de las familias campesinas, como hemos analizado, los bienes raíces, semovientes y en menor medida algunos mobiliarios; y, por otra, conectado con lo anterior, que a pesar de tener una riqueza patrimonial elevada los campesinos castellanos leoneses no trataban de buscar el rasgo distintivo en la posesión simbólica de objetos de adorno de gran valor tanto doméstico como personal (joyas-alhajas que son los que presentaban una mayor tasación) ${ }^{38}$.

Si este es el punto de partida, ¿hay realmente diferencias en las condiciones de vida de estas familias campesinas? $Y$ en caso afirmativo, ¿dónde se aprecian mejor tales elementos distintivos?

Falta información sobre el interior de sus casas, pero sí podemos intuir que, al igual que ocurre con los campesinos castellanos de la localidad vallisoletana de Cigales y los de La Mancha, se tiende a una especialización de las mismas a partir de la segunda mitad del siglo XVIII, con tareas domésticas desarrolladas en lugares específicos ${ }^{39}$. De este modo, en el inventario de 1755 de Diego López de la Torre y su esposa, vecinos de Comunión, los cuales poseen un patrimonio elevado de 56.773 reales, ya se menciona una "sala nueva" y otra "sala vieja". El mobiliario y la decoración de las mismas presentan modificaciones muy significativas: muebles y objetos decorativos relacionados con los nuevos gustos burgueses, tales como sillas de baqueta, cuadros "fábrica de Aragón" y un espejo pequeño con su marco ${ }^{40}$. Además, se aprecia como también disminuyen las piezas del mobiliario y desaparecen las camas, lo cual muestra una simplificación de las funciones, dando más importancia a las de relación social y conservando todavía la de guarda de objetos, pero de mayor valor: cucharas y alhajas de plata ${ }^{41}$. Junto a la sala nueva es sobre todo en la ropa personal donde volvemos a encontrar las nuevas prendas de la moda llegada desde Francia a comienzos del siglo XVIII ${ }^{42}$. Así, aunque parte de la ropa personal no es ni inventariada ni tasada debido a que se dieron a familiares, el valor de su tasación ascendió a 636 reales, cantidad muy próxima al mobiliario de la casa y sólo muy distante de la ropa de la cama, que es abundante pero sin cambios. Y en la vestimenta masculina hay corbatas, un sombrero y dos vestidos: con las respectivas casacas, chupas y calzones "de paño negro usado" 43 .

38 Al igual que habíamos observado en el resto del campesinado castellano leonés, sorprende la escasa presencia de piezas de cubertería y alhajas de uso personal en las familias campesinas analizadas, la media es de sólo 60 reales. Podemos recordar que en la de la localidad vallisoletana con altos niveles patrimoniales, las medias en la segunda mitad del siglo XVIII no superan ni tan siquiera los 5 reales. En la comarca de Sahagún la media baja a los 2'5 reales. En cambio, en la zona de la Bañeza-Astorga los valores medios se sitúan entre 151 y 184 reales.

39 En el entorno de Cigales a mediados del siglo XVIII se aprecia una mayor distribución y diferenciación de las dependencias. $\mathrm{M}^{\mathrm{a}} \mathrm{A}$. Sobaler Seco, "Algunas reflexiones sobre los interiores domésticos del entorno rural vallisoletano en el siglo XVIII" (texto inédito. Avance ofrecido en el Congreso Internacional Familias e Individuos: Patrones de Modernidad y Cambio Social (Siglos XVII-XIX), Murcia, 2013). C. Hernández López, "Cultura material y especialización...", p. 27.

40 AHMME, S/C

41 En concreto, se inventarían en la sala nueva seis cucharas de plata, un barquillo, una campanilla con su cadenilla, unas hebillas, un coralito con su cabo de plata, medallitas, dos relicarios, un cascabel, dos crucifijos y dos limpiadientes. Todo valorado en 317 reales; ibidem.

42 A. Giorgi, "La difusión del vestido francés", en Ciudadanos y familias. Individuos y práctica sociocultural hispana (siglos XVII-XIX), Valladolid, 2104, pp. 235-245

43 Valorados en 142 reales; AHMME,S/C 
Ahora bien, como se apreciaba con los campesinos del interior de Castilla, esta mayor tendencia hacia el consumo de nuevas modas no está tan relacionada con la riqueza patrimonial. De este modo, hay familias campesinas, como ejemplifica el vecino de Arminón José de Mana, quien a pesar de tener un nivel patrimonial que estaría dentro de la media, 14.898 reales, cuando se realiza su inventario, en la fecha ya avanzada del 1772, sólo sobresaldrá por la abundante ropa de cama, 949 reales, y en cambio, exceptuando una chocolatera y un asador, no se aprecia ninguna innovación, ni tampoco ningún objeto tendente al lujo. Su ropa destinada a cubrir el cuerpo es muy tradicional y únicamente tendrá una valoración de 136 reales $^{44}$. En el caso contrario, encontramos familias de muy escasos patrimonios, pero ya con innovaciones en los interiores domésticos o las apariencias externas. Tenemos varios ejemplos, pero se pueden sintetizar en Pedro de Gamarra, vecino de Miranda de Ebro, que tiene un patrimonio de 6.898 reales y en sus estancias aparece la importante novedad de un armario ${ }^{45}$, sillas de cocina, un espejo con su marco, dos candeleros de bronce y un vestido del difunto de lana tasado en 100 reales $^{46}$. En 1772, el inventario de José de la Plaza, vecino de Estavillo, carece de tasación, pero, con escasos bienes raíces, en cambio cuenta con un ropero personal donde junto a las piezas tradicionales destacan: un sombrero, unos calzones, dos chupas e incluso un chaleco con sus botones ${ }^{47}$. Y finalmente, en casa de la viuda Catalina Barrio, vecina de Puente la Rada, con un patrimonio muy reducido, 2.119 reales, de los cuales las deudas rondan los 253 reales, predominan claramente los bienes mobiliarios, pero donde sobresale la ropa de cama, con 524 reales de valoración, seguida por los útiles cocina, y en el que hallamos cinco cuadros valorados en 43 reales y ropa personal masculina con prendas de moda: dos chupas y tres calzones ${ }^{48}$.

\section{EL DESCENSO PATRIMONIAL Y LAS NUEVAS MODAS BURGUESAS EN LA PRIMERA MITAD DEL SIGLO XIX}

Lo primero que sorprende es que la riqueza patrimonial en la zona norte de Castilla, Miranda de Ebro y su entorno, experimenta un fuerte descenso en la primera mitad del siglo XIX, pasando las medias de 12.467 reales a 8.468 reales. Es más, los contrastes internos son todavía mucho más marcados ${ }^{49}$. Quizá fue una zona más castigada por los conflictos y guerras con la Francia revolucionaria (Guerra de la Convención) y más tarde durante la Guerra de la Independencia y su recuperación posterior fue más lenta, pero lo cierto es que estos menores patrimonios campesinos son un elemento diferencial respecto a la Castilla interior, e incluso al área también periférica de El Bierzo leonés. Así, cabe recordar que mientras que en la localidad vallisoletana de San Pedro de Latarce y en la comarca de Sahagún el crecimiento es más moderado -de 42.900 reales a 47.690 en San Pedro y de 9.863 reales a 12.335 reales en Sahagún-, en cambio, serán las bercianas las que ofrezcan una subida más significativa: de 8.251 a 12.250 reales de media ${ }^{50}$.

44 Ibídem.

45 De pino tasado en 22 reales. D. Roche se refiere al armario como una pieza clave del mobiliario del pueblo de París en el siglo XVIII. D. Roche, Le peuple de Paris, Paris, Aubier Montaigne, 1981, pp. 149-150.

$46 \mathrm{Y}$ también cuatro camisas de hombre valoradas en 44 reales. AHMME, S/C

47 Idem.

48 Las chupas y dos calzones de paño de Tarazona; ibidem.

49 Con patrimonios que llegan a los 24.928 reales y otros que no superan los 2.000 reales. AHMME,S/C

50 Un incremento del 539'7 \% que superaría con creces la media inflacionista de 238 ' $6 \%$. No obstante, estarían en las medias de los campesinos de la comarca de Sahagún y por debajo de los modestos o autosuficientes de la Vega Baja del Esla, que representan el $30 \%$ en el siglo XVIII; J. M. Pérez García, 
Como consecuencia de esta caída de los niveles de riqueza tasada el porcentaje de los bienes raíces es mucho más elevado en la estructura de sus patrimonios -destacando las casas y dependencias complementarias, equiparadas, con un 30'7 \%, a las tierras, 30'8 \%- respecto a la riqueza mobiliaria, la cual baja a un 28'7 \%. Además, se producirá una caída muy fuerte de las medias de los bienes mobiliarios, pasando de 6.031 reales a tan sólo 1.846. Graneros y despensas menos colmados de productos agrarios, inferiores deudas a favor de las economías campesinas y mayor peso relativo de los objetos simbólicos de sus condiciones de vida: ropa, muebles, útiles cocina, etc., los cuales llegan a representar el 75 '3 \% de los bienes mobiliarios, cuando en la segunda mitad del siglo XVIII no superaban el 24 \%. De ahí, la explicación de que esos enseres de civilización también experimenten un descenso, pero no tan fuerte como los anteriores, y se sitúen estancados en una media de 1.391 reales frente a los ya mencionados 1.429 reales de la segunda mitad del siglo XVIII.

Escasa disminución en este tipo de bienes que sigue la dinámica, aunque con menor intensidad, del campesinado castellano y leonés del interior, exceptuando el de la zona de Sahagún. Así, en la localidad vallisoletana pasan de 2.995 reales en la segunda mitad del Setecientos a 1.908 reales en la primera mitad del siglo XIX, mientras que entre las bercianas las medias por vecino son inferiores en todos los capítulos, con la única excepción del mobiliario de la casa (126 reales sobre 111), debido en gran parte a la presencia de arcones para el almacenaje del grano. Sólo en la zona de Sahagún se aprecia una sustancial mejoría con respecto al siglo XVIII, subiendo de 839 reales a 3.429 reales, sobre todo entre las familias con una tasación patrimonial por encima de los $20.000^{51}$.

Como ya se ha demostrado, mayores niveles de riqueza patrimonial no significan claramente una mayor tendencia al consumo y una mejora de las condiciones materiales de la vida cotidiana, ya que para las familias campesinas es más importante, debido a sus economías, la inversión en bienes raíces, ganadería y útiles de labranza ${ }^{52}$.

No obstante, aunque los niveles cuantitativos de los objetos que conforman las condiciones de vida permanezcan casi estancados ¿es posible que, al igual que sucede con los restantes campesinos castellanos y leoneses, la llegada de las novedades en los mismos se produjese independientemente de la riqueza patrimonial?

Las tendencias en las nuevas modas se manifiesta de forma muy clara sobre todo en las ciudades de Burgos y León y en las familias burguesas de la administración y profesiones liberales, las del mundo de los negocios y también en las nobiliarias de segunda fila que no han abandonado sus residencias provinciales. De forma más tardía y con menor intensidad pasarán también al mundo rural, tal como se aprecia en algunos ejemplos descritos para el interior castellano. Los gustos más modernos se observan principalmente en los espacios domésticos -mobiliario y decoración de las estancias-y en las prendas de la vestimenta del cuerpo (así como en las joyas y alhajas de adorno).

Lo más relevante de las familias campesinas de la zona norte castellana, Miranda de Ebro y su jurisdicción, es que las nuevas modas llegan también a partir de los años

\footnotetext{
"Estructuras sociales y élites excedentarias en el contexto de una sociedad rural leonesa a finales del Antiguo Régimen", en Un modelo social leonés..., p. 129.

51 R. M. Dávila Corona y J...M: Bartolomé Bartolomé, "Condiciones de vida y pautas de consumo...”, p. 85.

52 Un ejemplo claro es el del campesinado berciano de la primera mitad del siglo XIX, el cual sacrificará su pobre nivel de vida con el objetivo de conseguir unos mayores bienes de producción. J.M. Bartolomé Bartolomé, La hegemonía de una nueva burguesía en El Bierzo (1800-1850). Las transformaciones económicas y sociales durante la crisis del Antiguo Régimen, León, Universidad, 2000, p. 147. En cambio, esta realidad no se aprecia en la Vega Baja del Esla, donde los bienes muebles resisten bien la aceleración de los precios; J.M. Pérez García, "Evolución de los niveles de vida...", pp. 167-169.
} 
treinta del siglo XIX. Y lo hacen a pesar de esos descensos tan claros en las riquezas de sus patrimonios y de forma independiente al nivel de los mismos. Además, las novedades burguesas aparecerán en el mobiliario y también en las piezas decorativas de las estancias, pero, principalmente y casi de forma exclusiva, en las apariencias externas y en la vestimenta de sus cuerpos de cara a la comunidad.

Así, en la familia campesina que cuenta con un patrimonio más elevado, muy por encima de la media, 24.928 reales -se trata de José Varona y su mujer Josefa de Cuéllar, vecinos de Pancorbo, cuyo inventario se realizó en 1835-, los bienes que muestran sus condiciones y estilo de vida también superan con creces la media del periodo, 4.304 reales; sin embargo, predomina la ropa de cama y de casa, valoradas en 2.209, es decir la mitad de dichos bienes, con ajuares muy tradicionales, donde sólo figura como novedad una colcha de percal ${ }^{53}$. Es cierto, que la presencia de cubiertos de plata y de libros proporcionan la imagen de un modelo vital más cultivado ${ }^{54}$. Pero no se aprecian muchas innovaciones ni en los muebles de la casa -únicamente mesas y sillas- ni en los elementos decorativos -dos espejos-, ni en las piezas de plata -todas ellas de cubertería-,concentrándose más, en cambio, en las ropas del difunto: junto a la tradicional capa de paño negro ${ }^{55}$, tres chaquetas, tres pantalones y tres chalecos. Las dos primeras prendas de paño pardo o negro y en cambio los chalecos de seda morada o de "mahón con forro de bombay" 56 . Vestimenta externa corporal que a pesar de su poca valoración, sólo 234 reales, está llena de novedades de tendencia burguesa.

Ahora bien, esta tendencia hacia una modernización en la demanda y consumo de artículos de moda no es exclusiva de los mayores patrimonios, tal como lo demuestra el comportamiento de la viuda Balbina Rosales, vecina también de Pancorbo, en $1834^{57}$. Su riqueza patrimonial es de únicamente 1.904 reales, poseyendo sólo un cerdo y útiles de labranza y el resto son bienes mobiliarios conectados con otra simbología de sus condiciones de vida. Entre las piezas del mobiliario, junto con las abundantes arcas, hay mesas, sillas y un armario pequeño, en los útiles de cocina, una chocolatera y parillas, pero siendo de nuevo en la indumentaria tanto masculina como femenina, que es la que tiene la mayor valoración con 633 reales, donde se concentren las innovaciones: pantalones y chaquetas de mahón, chalecos blancos de pana y cotonía, camisas de hombre nuevas, zapatos nuevos; un vestido de mujer, sayas de percal, pañuelos de seda y percal, uno de ellos encarnado $^{58}$. En definitiva, prendas modernas elaboradas con fibras también novedosas.

\section{CONCLUSIONES}

A lo largo del periodo analizado las condiciones de vida de las familias campesinas de la zona norte castellana, de las localidades de frontera de Miranda de Ebro y su jurisdicción, presentarán rasgos distintivos respecto al campesinado de las zonas del interior castellano y leonés.

53 Forrada con fondo verde, tasada en 40 reales; AHMME,S/C

54 "Una porción de libros de varias manos, en 40 reales" y los cubiertos de plata valorados en 359 reales; ibídem.

55 C. Bernis Madrazo, Indumentaria española en tiempos de Carlos V, Madrid, CSIC, 1956

56 AHMME, S/C

57 Ibídem.

58 En concreto el número de piezas es el siguiente: dos pantalones, dos chaquetas, tres chalecos, siete camisas de hombre, de las cuales cuatro son nuevas, un vestido, seis pañuelos, dos sayas y dos sayos; ibídem. 
En primer lugar, será diferente la dinámica de los niveles de sus patrimonios globales. Así, a lo largo del siglo XVIII y particularmente en la segunda mitad, ya con datos cuantitativos, podemos hablar de patrimonios solventes y próximos a los campesinos más pudientes de León. La sorpresa provendrá de los datos de la primera mitad del siglo XIX, donde se observa un descenso significativo de los mismos, sin la clara recuperación generalizada del resto de las economías campesinas a partir de los años treinta del nuevo siglo. Este empobrecimiento se traduce como es lógico en sus condiciones y estilos de vida, con un descenso de sus valores medios, aunque en menor medida que en las riquezas globales patrimoniales.

En segundo lugar, como es natural en la estructura de los patrimonios, son los bienes raíces, casas y sobre todo tierras, y semovientes, los predominantes. Sin embargo, los demás bienes mobiliarios, principalmente los productos agrarios de la despensa y las deudas a favor conectadas con las actividades agrarias, también tendrán un comportamiento distinto, que vendrá dado por su mayor valor comparativo en la segunda mitad del siglo XVIII y su menor peso en la primera del XIX. Lo cual es un nuevo síntoma del empobrecimiento de las economías campesinas de la zona norte, a partir de los años treinta del siglo XIX. Indudablemente, sus consecuencias serán una caída de las medias de los enseres u objetos que conforman las condiciones y estilo de vida, pero no tan intensas.

Finalmente, al margen de sus niveles de riqueza patrimonial y de las trayectorias cuantitativas descritas, lo cierto es que se produjeron interesantes cambios en los hábitos vitales de las familias campesinas de Miranda de Miranda de Ebro y su jurisdicción, los cuales son de más temprana aparición que en la zona de Valladolid o de León. De este modo, durante el siglo XVIII, sobre todo desde los años cincuenta, asistimos a una mayor especialización de los espacios domésticos: la llegada de salas nuevas a las casas, nuevos muebles y objetos decorativos: armarios, espejos, etc., y principalmente las novedades en la vestimenta personal, más en la ropa masculina, de influencia francesa, tan de moda en España según avanza el Setecientos a partir de la influencia de la Corte.

Y a partir de los años treinta del siglo XIX las innovaciones también serán más claras en la ropa personal, tanto masculina como femenina, de acuerdo con las nuevas modas burguesas y con prendas elaboradas ya con las nuevas fibras textiles: el algodón y sus variedades. Y lo que es más importante, este consumo de nuevos objetos y atuendos tampoco guarda una relación directa, tal como sucedía con los campesinos de Valladolid o León, con la mayor o menor riqueza patrimonial. El mimetismo no estaba reservado a los más pudientes ${ }^{59}$. Su presencia en los interiores domésticos de las familias campesinas 0 en sus roperos está al margen de (o no siempre coinciden con) sus medios económicos, lo cual vuelve a reafirmar el carácter complejo de sus demandas, aunque sean circunscritas a comunidades campesinas.

\section{BIBLIOGRAFÍA}

Bartolomé Bartolomé, J. M., "Condiciones de vida y privacidad cotidiana del campesinado leonés de Tierra de Campos: La comarca de Sahagún en el siglo XVIII", en F. Núñez Roldán (coord.), Ocio y vida cotidiana en el mundo hispánico moderno, Sevilla, Universidad de Sevilla, 2007, pp. 403-416.

- Prácticas hereditarias y transmisión de la propiedad en Tierra Campos leonesa: la comarca de Sahagún en el siglo XVIII", Revista de Demografía Histórica, XX-1, (2002), pp. 179-212.

59 D. Roche, La cultura material a través de la historia de la indumentaria, In: Historiografía francesa: corrientes temáticas y metodológicas recientes [en línea]. Mexico: Centro de estudios mexicanos y centroamericanos, 2000. http://books.openedition.org/cemca/626. 
- "Condiciones de vida y pautas de consumo del campesinado leonés de La Bañeza y Astorga (1750-1850)", en El mundo rural en la España Moderna. Actas de la VIIa Reunión Científica de la Fundación Española de Historia Moderna, Cuenca, Universidad de Castilla-La Mancha (2004), pp. 589-590.

- La hegemonía de una nueva burguesía en El Bierzo(1800-1850). Las transformaciones económicas y sociales durante la crisis del Antiguo Régimen, León, Universidad, 2000

- Familias de comerciantes y financieros de la ciudad de León (1700-1850), León, Universidad, 2009.

- "Pobrezas y riquezas campesinas castellano leonesas: Contrastes en las formas de vida y consumo (1700-1850)", Tiempos Modernos, 8, 3, (2016), pp. 419-431.

- "Niveles de riqueza patrimonial, condiciones de vida y pautas de consumo de las familias de comerciantes y financieros de la ciudad de León (1700-1850)", en F. Chacón Jiménez y C. J. Gómez Carrasco (coords.), Familia, recursos humanos y vida material, Murcia, Universidad, 2014, pp. 181-204.

- Interiores domésticos y Apariencias externas de las familias burguesas y nobles de la ciudad de León (1700-1850), León, Universidad, 2017.

Bartolomé Bartolomé, J. M. y García Fernández, M. (dirs.), Apariencias contrastadas: contraste de apariencias. Cultura material y consumos de antiguo régimen, León, Universidad, 2012.

Barbosa Vilaça, O., "A casa rural do Baixo Minho (1750-1810)", Revista de Estudos históricos, 29, 57, (2016), pp.235-262

Bernis Madrazo, C., Indumentaria española en tiempos de Carlos V, Madrid, CSIC, 1956

Casado Lobato, C. y Carrerira Vérez, A., Viajeros por León. Siglos XII-XIX, Madrid, Santiago García, 1985.

Cruz Valenciano, J., El surgimiento de la cultura burguesa. Personas, hogares y ciudades en la España del siglo XIX, Madrid, Siglo XXI, 2014.

Dávila Corona, R. Ma . y Bartolomé Bartolomé, J. M., "Condiciones de vida y pautas de consumo en la Castilla rural (1750-1850)", en J. M. Bartolomé Bartolomé y M. García Fernández (dirs.), Apariencias contrastadas:contraste de apariencias. Cultura material y consumos de antiguo régimen, León, Universidad, 2012, pp. 79-99.

De Vries, J., La revolución industriosa. Consumo y economía doméstica desde 1650 hasta el presente, Barcelona, Crítica, 2009

Elias, N., El proceso de la civilización. Investigaciones sociogenéticas y psicognéticas, México-Madrid-Buenos Aires, FCE, 1987.

Eiras Roel, A., "Inventarios post-mortem, consumo y niveles de vida del campesinado del Antiguo Régimen (Problemas metodológicos a la luz de la investigación internacional)", VII Congreso de Historia Agraria, Salamanca, Universidad, 1997, pp. 46-53.

García Fernández, M., "Vidas cotidianas en el entorno rural del Duero: niveles de consumo comparados. Siglo XVIII", en Campo y campesinos en la España Moderna, Actas XII Reunión Científica de la Fundación Española de Historia Moderna, León, FEHM, 2012, pp. 1.151-1.164.

García González, F., Las estrategias de la diferencia. Familia y reproducción social en la sierra (Alcaraz, siglo XVIII), Madrid, Ministerio de Agricultura, 2001

Giorgi, A. "La difusión del vestido francés", en M. García Fernández y F. Chacón Jiménez (dirs.), Ciudadanos y familias. Individuos y práctica sociocultural hispana (siglos XVIIXIX), Valladolid, Universidad, 2104, pp. 235-245

Hernández López, C., "Cultura material y especialización de la casa (Campo de Montiel, 1650-1850)", en J. M. Bartolomé Bartolomé y M. García Fernández (dirs.), Apariencias contrastadas: contraste de apariencias. Cultura material y consumos de antiguo 
régimen, León, Universidad, 2012, pp. 15-40

Ibañez Rodríguez, S., "La necesidad de medir. La metrodología agraria del Antiguo Régimen en la Rioja", Brocar, 19, (1995), pp. 131-163.

Imízcoz Beunza, J. M. (ed.), Élites, Poder y Red Social. Las élites del País Vasco y Navarra en la Edad Moderna (estado de la cuestión y perspectivas), Bilbao, Universidad del País Vasco, 1996.

- Casa, Familia y sociedad, País Vasco, España y América, siglos XV-XIX, Bilbao, Universidad del País Vasco, 2004.

- "Una modernidad diferencial. Cambio y resistencias al cambio en las tierras vascas, 1700-1833", Historia Social, 89, (2017), pp. 79-102.

- "Costumbres en tensión. El proceso de la civilización en las tierras vascas, de las costumbres compartidas a la fractura de la comunidad (1700-1833)", en J. M. Imízcoz Beunza, M. García Fernández y J. Esteban Ochoa (coords.), Procesos de civilización: cultura de élites, culturas populares. Una historia de contrastes y tensiones (siglos XVI-XIX), Bilbao, Universidad del País Vasco, 2019.

Imízcoz Beunza, J. M. y Artola Renedo, A., Presentación del Dossier "Redes sociales, procesos de cambio cultural y conflicto en las provincias vascas y navarras (17001839)", Historia Social, 89, (2017), pp. 73-77.

Isla J. F. de, Historia del famoso predicador fray Gerundio de Campazas, alias Zotes (edición de Rodríguez Cepeda), tomo II, cap. IX, 1995.

Manzanos Arreal, P., "La casa y la vida material en el hogar. Necesidades vitales y niveles de vida en la Vitoria del siglo XVIII", en J. M. Imízcoz Beunza (coord.), Vida cotidiana en Vitoria en la Edad Moderna y Contemporánea, San Sebastián, Txertoa, 1995, pp. 199-237.

Pérez Álvarez, M. J. y Rubio Pérez, L., "Familia y comunidad rural. Modelos agrarios, colectivismo social y comportamientos familiares en la provincia de León durante la Edad Moderna", Studia Histórica. Historia Moderna, 36, (2014), pp. 177-201.

Pérez García, J. M., "Estructuras familiares, prácticas hereditarias y reproducción social en la Vega Baja del Esla (1700-1850)", en Un modelo social leonés en crecimiento: La Vega Baja del Esla entre 1700 y 1850, León, Universidad, 1998, pp. 85-109.

- "Niveaux de vie et traditions culturelles dans les campagnes du León entre 1700-et 1850", en Histoire \& Sociétés Rurales, (1997), 8, pp. 61-92

Ramos Palencia, F., "Notas metodológicas sobre la utilización de los inventarios postmortem: Clasificación de bienes de consumo, base de datos e impacto de créditos y deudas, 1700-1850", en D. Muñoz Navarro, (ed.), Comprar, Vender y Consumir. Nuevas aportaciones a la historia del consumo en la España moderna, Valencia, Universidad, 2011, pp. 21-54.

Rey Castelao, O., "Casas y cosas en la Galicia occidental en el siglo XVIII", Cuadernos de Historia Moderna, extra 14, (2015), pp. 221-223.

Roche, D., Le peuple de Paris, Paris, Aubier Montaigne, 1981

- La culture des apparences. Une histoire du vêtement XVII-XVIII siècle, París, Fayard, 1989.

- Histoire des coses banales. Naissance de la consommation XVII-XIX siècle, París, Fayard, 1997

- La cultura material a través de la historia de la indumentaria, en Historiografía francesa: corrientes temáticas y metodológicas recientes [en línea]. Mexico, Centro de estudios mexicanos y centroamericanos, 2000. http://books.openedition.org/cemca/626.

Rubio Pérez, L., "Campo, campesinos y cuestión rural en Castilla la Vieja y en el Reino de León durante la Edad Moderna. Estado de la cuestión, claves y valoraciones de 
conjunto", Studia Histórica. Historia Moderna, 29, (2007), pp. 131-177.

Sarti, R., Vida en familia. Casa, comida y vestido en la Europa moderna, Barcelona, Crítica, 2002.

Sobrado Correa, H., "Algunas notas acerca de la vida cotidiana del campesinado gallego en la Edad Moderna", Revista Portuguesa de História, XLVII, (2016), pp. 129-152.

Sobaler Seco, M. Á., "Algunas reflexiones sobre los interiores domésticos del entorno rural vallisoletano en el siglo XVIII" (texto inédito. Avance ofrecido en el Congreso Internacional Familias e Individuos: Patrones de Modernidad y Cambio Social (siglos XVII-XIX), Murcia, 2013.

Yun Casalilla, B., "Inventarios post-mortem, consumo y niveles de vida del campesinado del Antiguo Régimen (Problemas metodológicos a la luz de la investigación internacional)", VII Congreso de Historia Agraria, Salamanca, Universidad, 1997, pp. 46-53. 